\title{
Mutation Breeding and Biofertilizers
}

\author{
Dheya P Yousif Falih Hasan Saeed Usama Abedall Alwan* \\ Ministry of Science and Technology, Agriculture Research Directorate, Iraq
}

*Corresponding author: Dheya P Yousif Falih Hasan Saeed Usama Abedall Alwan,

Ministry of Science and Technology, Agriculture Research Directorate, Iraq.

Received Date: December 23, 2019

Published Date: January 14, 2020

\section{Introduction}

Mutation breeding is one of the valuable breeding techniques. Ionizing radiation, especially -rays, has been used for several decades to produce new plant varieties. In addition, mutationbreeding technology using ion beam irradiation has undergone major developments in recent years and has been applied to various bio resources such as ornamental plants, crops and industrial microbes. Ion-beam mutation-breeding technology will be a promise way to produce biofertilizers/ biopesticides inoculants for the next generation. Globally, several collaborative studies have started to improve the phenotype of inoculants using the ion beam irradiation facility. The objectives are to apply the gamma rays in addition to the ion beam irradiation in an experimental project so as to access to the optimum source of radiation dose and to investigate the mass production inoculants which can develop the organic agriculture and serves the ecological- agricultural systems.

\section{Justifications}

in general, establishment of environmentally friendly sustainable agriculture and reduction of agrochemical input are required not for Iraq and west Asia, but all over the world. Biofertilizer production Project aims to produce new strains and inoculants for several biofertilizers such as Trichoderma spp. and Rhizobial spp. which have more desirable agricultural traits so as to reduce the chemical fertilizers applied which increase the availability of plant nutrients from soil and decline the inputs costs without decreasing crop yield . biofertilizers researchers in Iraq attempt to initiate with a project attend in devoting efforts to three objectives which as follows:

- Conventional development of multi-functional biofertilizer, which consists of multiple inoculants with promoting plant growth or inhibiting plant diseases, and to improve microbial inoculants with high Density, high effectiveness and long time period such as Trichoderma spp.
- Improving of inoculants by radiation-based microbial mutation breeding in order to keep high quality of inoculants under tropical conditions and to assess the radiation sensitivity and the useful gamma rays doses.

- Dissemination of radiation sterilization method of carrier using Co-60 to improve quality of carrier for biofertilizer.

Trichoderma spp. and the Whole Efforts and Benefits

Although, Trichoderma spp. inoculants is a clean technology for sustainable agriculture, Trichooderma inoculants have been used as an environmentally friendly source to:

- $\quad$ Control of root and foliar pathogens

- $\quad$ Changes in the micro floral composition on roots

- $\quad$ Enhanced nutrient uptake, including but not limited to nitrogen

- $\quad$ Enhanced solubilization of soil nutrients.

- $\quad$ Deeper rooting

- $\quad$ Enhanced root development

- Increased root hairs formation

There are several forms of trichoderma inoculants available, including solid or liquid forms that can maintain the survival of effective trichoderma at the level of 108 cells/g for at least for 6 months, Even though the liquid form of trichoderma inoculants is applied in the production process more easily than solid form. The survival of trichoderma cell in liquid inoculants depends on the nature of trichoderma strain and polymeric additive substance incorporated into liquid inoculants formulation. Thus, solid inoculants, especially those using peat-based carrier, are still popular for biofertilizer inoculants production. However, 
peat is limited in many countries including Iraq, so it is necessary to find out carriers that are locally available for commercial scale production. The appropriate material to be used as a carrier in trichoderma or bio-fertilizer inoculants production should be nontoxic material, have good water holding capacity, support bacterial growth and survival, be easily prepared in powder form, and have nearly neutral $\mathrm{pH}$, the quality of inoculants is varied according to the physicochemical and biological properties of material as well as the sterilization method applied to carrier. Since, contaminant microorganism is the main problem that affects the quality and shelf-life of trichoderma inoculants. Sterilized carrier is necessary to be accomplished prior injection of the pure culture of trichoderma into carrier. It is necessary to develop advanced trichoderma biofertilizers that keep the number of viable inoculants for a definite period of time.

\section{Acknowledgment}

None.

\section{Conflict of Interest}

No conflict of interest. 